\title{
Editorial
}

\section{Meteorological Impacts on Landform Changes}

\author{
Hongming He, ${ }^{1}$ Zhongping Lai, ${ }^{2}$ and Steffen Mischke ${ }^{3}$ \\ ${ }^{1}$ Institute of Soil and Water Conservation, Northwest Agriculture and Forestry University and Chinese Academy of Sciences \\ and Ministry of Water Resources, No. 26 Xinong Road, Yangling, Shaanxi 712100, China \\ ${ }^{2}$ School of Earth Sciences, China Geosciences University (Wuhan), No. 388 Lumo Road, Hongshan, Wuhan, Hubei 430074, China \\ ${ }^{3}$ Faculty of Earth Sciences, University of Iceland, Sturlugata 7, 101 Reykjavik, Iceland
}

Correspondence should be addressed to Hongming He; hongming.he@yahoo.com

Received 29 October 2015; Accepted 29 October 2015

Copyright (c) 2016 Hongming He et al. This is an open access article distributed under the Creative Commons Attribution License, which permits unrestricted use, distribution, and reproduction in any medium, provided the original work is properly cited.

\section{Introduction}

Surface landforms are influenced by various forces, such as natural processes and human activities, over long-term periods of time. Landform is the primary issue that we need to understand while addressing global change and the impact of anthropogenic activities on the environment and the past processes. Landform evolution is an important aspect of Earth Sciences and involves complicated interaction among different physical processes and environmental factors, such as topography, underlying rock types and structures, tectonics, climate, vegetation, and human activities, all occurring over a wide range of spatial and temporal scales. Different landform patterns are derived from tectonic movements and erosion and accumulation in specific meteorological settings. The exogenic meteorological forces control the hydrological conditions, the regional vegetation and fauna, and the mode and efficiency of weathering processes. Preserved and changing landforms recorded and registered the meteorological conditions in the past and at present, and future topographical conditions can be simulated for changing meteorological parameters. The investigation of meteorological impacts on the landform can improve the understanding of characteristics and processes of landform evolution and provide scientific support for the protection of the environment, for the maintenance of functioning rivers in sustainable landscape settings. We invited investigations to contribute original research articles as well as review articles that explored this issue from new aspects and used new methodologies.

\section{Climate Change}

J. Fei et al. discussed the hypothesis that geological events dramatically affected the weather and environment in China and the Korean Peninsula in historical times. The results of their study suggest that widespread epidemics occurred in the summer and autumn of $1601 \mathrm{AD}$ in China and Korea and they suppose that the Huaynaputina eruption possesses a major burden of responsibility for these concurrent epidemic outbreaks. Then, C. Li et al. take a closer into the characteristics of marine isotope stage 3 (MIS 3) and lake records of upper stream of Yangtze River in Millennial-scale Asian monsoon and the authors suggest that signals of the Dansgaard-Oeschger (DO) events were possibly transmitted to the lake evolution by Asian monsoon.

C. Zhao et al. reconstruct a vegetation succession history, explore vegetation succession responses to climate change (especially during the Holocene Megathermal), and provide evidence for the evaluation of the possible effects of future climate change. The result of their work suggests that vegetation experienced five successions from cold temperature mixed coniferous and broadleaved forest, to forest-steppe, steppe-woodland, steppe, and finally meadow-woodland in Holocene. And the Holocene warm period in NE China (7800-7300 cal yr B.P.) could have resulted in strengthening of precipitation in northernmost NE China and encouraged the development of broadleaved forests. T. Ning et al. analyzed temporal and spatial normalized difference vegetation index (NDVI) changes on the northern Loess Plateau and their correlation with climatic factors from 1998 to 2012. As 
a result, they detected positive effects of human activities, including the "Grain for Green" program and successful environmental treatments at coal mining bases, in addition to other factors that improved the vegetation state.

V. Macura et al. focus on determination of the effect of water depth and flow velocity on the quality of an instream habitat in terms of climate change using Instream Flow Incremental Methodology (IFIM). They investigated an optimum ratio of the weights of the flow velocity and water depth for an assessment of the quality of an instream habitat. Furthermore, H. Yao et al. examine the reductions of the runoff and sediment load of the upper Yellow River and separated the effects of climate change and human activities. Their results show that human activities are the major drivers of the runoff and sediment load variations in the Xiliugou basin, while climate change also contributed to the observed reductions.

\section{Soil Erosion}

N. N. Cheng et al. investigate the impacts of hydrometeorological changes on the evolution of erosive landforms in the Loess Plateau in the past 60 years (1950-2010). The result of their study shows that erosive landforms were largely shaped by hydrometeorological characteristics in comparison with other contributors. It shows that there is strong positive relationship between precipitation and erosion. In addition, C. Wang et al. investigated the sediment budget of the river mouth reach of the Yangtze River. The results demonstrate that the river mouth reach acted as a sink but not as a source due to impoundment measures, which exacerbates the decrease of sediment discharge into the sea. The authors also discuss that uncertainties exist in examination of the sediment processes due to insufficient datasets as well as deficiencies in the methodologies used to calculate changes in river channels.

S. S. Shin et al. propose a new equation of power law based on the rainfall power theory under the ideal assumption that drop-size is uniformly distributed in constant rainfall intensity. In addition, they evaluated rainfall energy through comparing between existing empirical equations and equation of rainfall power. This result supports the conclusion that the rainfall energy equations can be more useful in the development of soil erosion models due to significant increase in sediment yield by increasing transport capacity of surface runoff in the high rainfall intensity. Moreover, $\mathrm{H}$. Yao et al. also suggest that different influences rates of rainfall (climate change, human activities) change to the deviations of runoff and sediment load could be produced by using different categories of annual precipitation. Thus, researchers need to pay attention to the effects of rainfall intensity to avoid overestimating or underestimating the contributions of rainfall changes to the variations of runoff and sediment load. Moreover, a further inspection on the changes flow frequency distribution and the water-sediment indicated that the implementation of soil and water conservation measures should be the main reason for the phenomenon.

$\mathrm{H}$. Sun et al. conducted a set of sensitivity experiments under conditions of low and high orography in the northern
Tibetan Plateau (TP) using a regional climate model with and without the dust module to further discuss the dust distribution and the impacts of dust effects in TP and East Asia. As the condition of the northern TP uplift to present altitude, the effect of dust delays the East Asia summer monsoon onset in the southern and northern monsoon regions and greatly suppresses precipitation in East Asia compared with results in the low terrain experiments.

\section{Hydrometeorology}

Y. He et al. investigate temporal and spatial variation characteristics of precipitation of flood season. The results show that precipitation is affected by the large-scale circulation patterns. Thus, they show the current trends of precipitation increase in the Yangtze River catchment will likely continue in the future. B. Jun identifies the morphological changes associated with the soil erosion flow and determines the affected area and total volume of debris flow. He revealed both the area affected by the flow and the spatial distribution of sediments with reasonable accuracy for most of the study area, and considerate for technicians dealing with the protection of the mountain area from intense rainfall. Y. Cheng studied the analysis of the effects of precipitation and anthropogenic activity on hydrologic features in Yanhe during 1961 to 2008 in support for regional water management and evaluation of soil and water conservation practices. He shows not only that the monthly distribution of precipitation and runoff and sediment discharge is extremely uneven in the river basin, but also that the precipitation decreased in most seasons except in winter with particularly decreasing precipitation in fall.

Finally, the presented papers cover various fields of research (climate change, soil erosion, hydrometeorology, etc.) impressively highlighting the versatility of the model in general and specifically in the field of landform evolution such as the Riverine HABitat SIMulation (RHABSIM) model which determines the quality of an aquatic habitat based on the preferences of fish for a wider range of discharges; Community Land Model version4 (CLM4) which investigates response of stream flow to land use cover change and climate change; Soil and Water Assessment Tool (SWAT) and Geographic Information System (GIS), and so forth. Moreover, most of the presented studies focus on adverse effects of climate change and anthropogenic activities like Yangtze River, Loess Plateau, and so forth. The individual articles highlight the need of further improvements and developments.

\section{Acknowledgments}

We acknowledge with gratitude the research grants kindly provided by the Hundred-Talent Project of the Chinese Academy of Sciences (Dr. H. M. He, 2011009), the Innovation Frontier Project of Institute of Soil and Water Conservation of the Chinese Academy of Sciences (10502), Key Research Program of the Chinese Academy of Sciences (Grant no. KZZD-EW-04), Strategic Priority Research Program of the Chinese Academy of Sciences (Grant no. XDB03020300), the State Key Laboratory of Soil Erosion and Dryland Farming on 
the Loess Plateau (10501-192), and the State Key Laboratory of Soil Erosion and Dryland Farming on the Loess Plateau (K318009902-1402).

Hongming $\mathrm{He}$

Zhongping Lai Steffen Mischke 

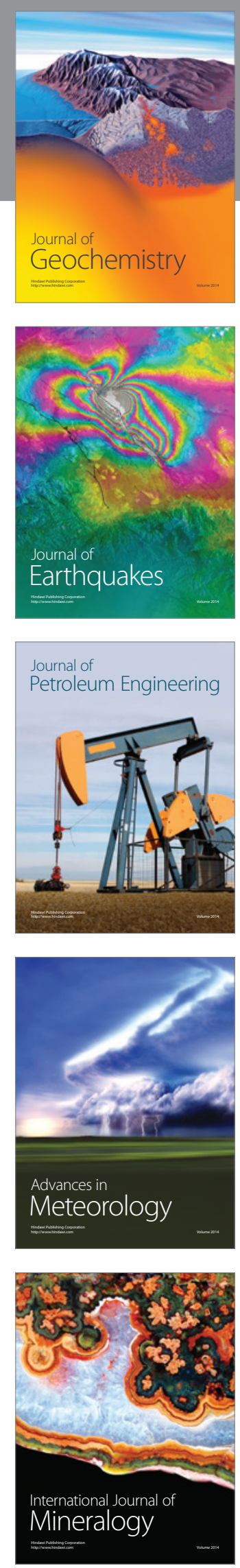
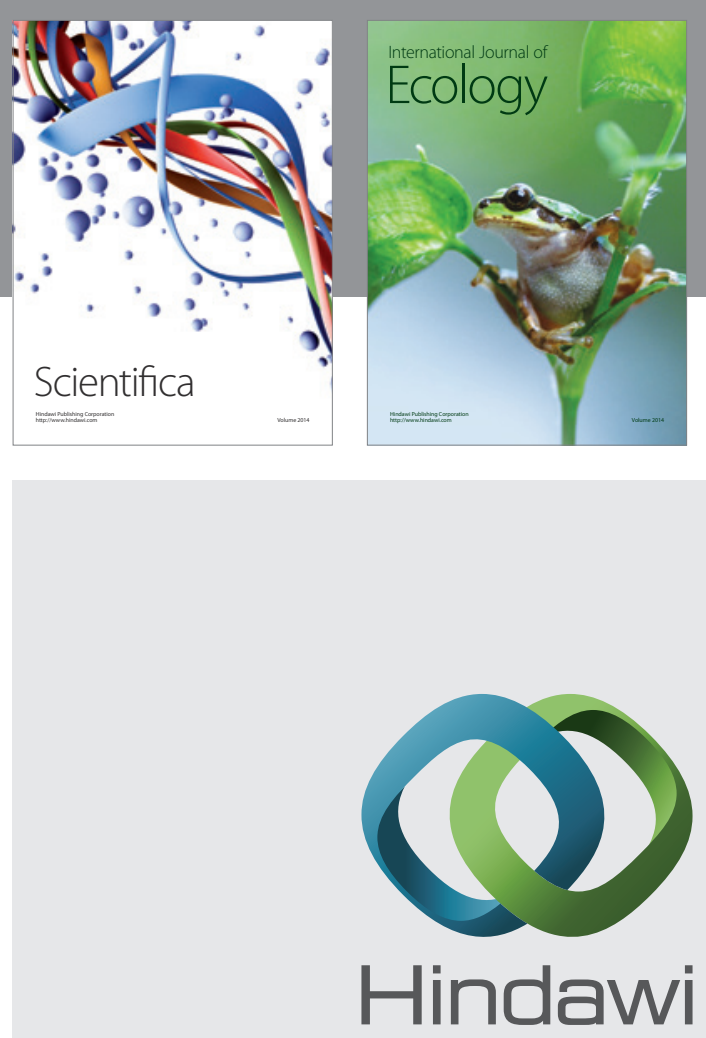

Submit your manuscripts at

http://www.hindawi.com
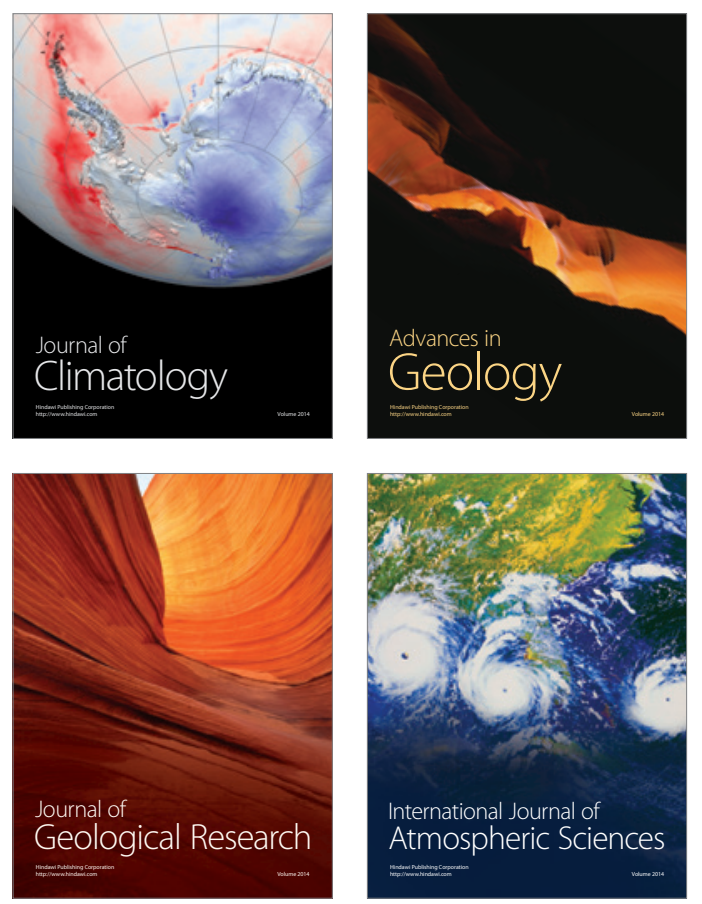

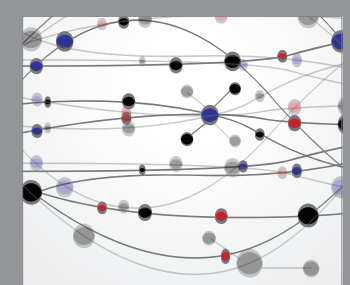

The Scientific

\section{World Journal}
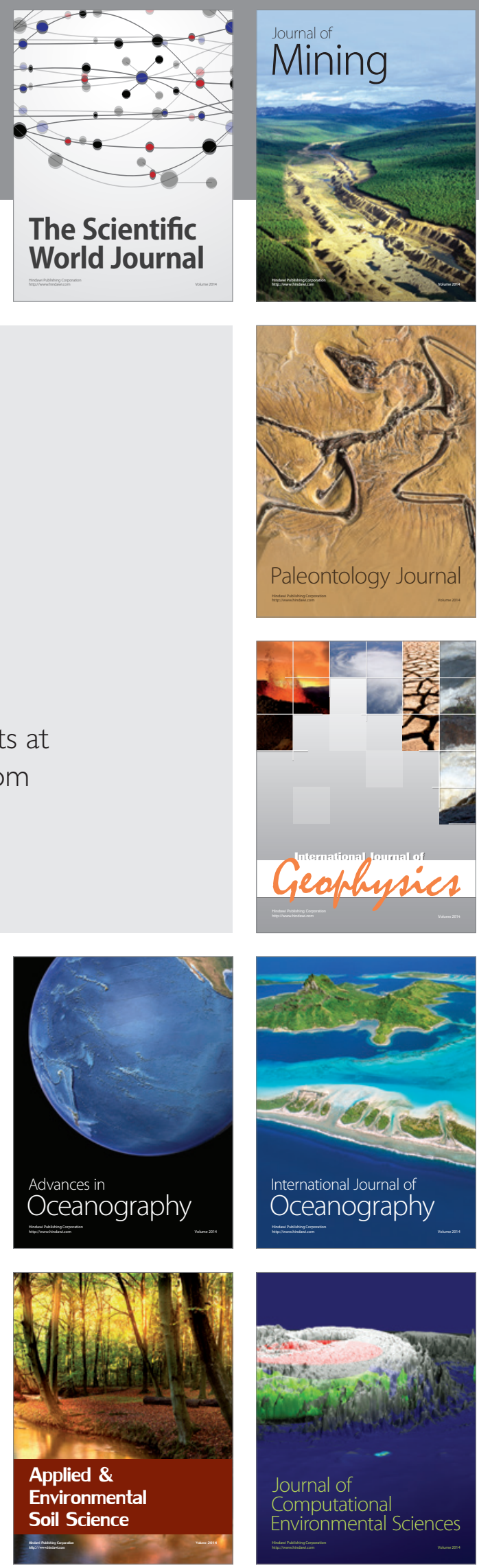